pachymeningitis, arachnoid cyst or adhesive arachnoiditis, may require laminectomy. In these days intrathecal streptomycin would have to be considered.

8. Symptoms. Analgesics for pain and headache, hypnotics for insomnia, aperients or enemata or both for constipation, iron for anaemia and nutritious diet in convalescence.

\section{Prevention}

Pasteurization or boiling of milk would eliminate brucellosis except in those whose work brings them in contact with infected animals or their carcases, and laboratory workers. Complete eradication of the disease in humans depends on its eradication in animals. This has been achieved in Norway as a result of laws which stated that aborting animals must be reported and tested, and that the owner of infected animals must not allow his animals to have a chance of infecting those of other owners. Infected animals were marked and could only leave the farm for slaughter.

Methods of eradication must vary according to the veterinary problems of the particular country but consist essentially of (i) elimination of infected animals (detected by the agglutination test) anf (ii) vaccination of animals. In Great Britain:brucellosis does not occur in pigs, goats or sheep It occurs only in bovines and is almost entirelyo due to $B r$. abortus. In bovines, vaccination witho an attenuated strain of $\mathrm{Br}$. abortus (Strain 19 os S.I9) has given valuable results.

\section{Acknowledgments}

I am indebted to the Wellcome Museum of Medical Science for illustrations I, 3, 4 and 5, and $\vec{\psi}$ to Professor Stableforth, Director of the Veterinaryo Fisheries, for Fig. 2.

\section{BIBLIOGRAPHY}

'Brucellosis: A Symposium' (1950), American Association for the Advancement of Science.

DALRYMPLE-CHAMPNEYS, W. (1950), Lancet, i, 429, 477. HARRIS, H. J. (1950), 'Brucellosis,' New York.

MARSTON, J. A. (1850), Army Medical Report of 1863,3 , ROGER, H., and POURSINES, Y. (1938), Marseille-méd., 2, 63. STABLEFORTH, A. W. (1952), Proc. Roy. Soc. Med., 45 (2) 79-86 (veterinary).

\title{
SURGICAL REPLACEMENT THERAPY
}

\author{
By Michael F. A. WoodrufF, M.S., F.R.C.S. \\ Department of Surgery, University of Aberdeen
}

\section{Basic Principles}

Whenever important structures are congenitally absent or irreparably damaged by injury or disease, the problem of replacement arises. In many cases no solution can be found; recently, however, surgeons have become increasingly interested in the problem and important advances have been made.

The methods of replacement now being used may be classified under three main headings :

I. Autotransplantation (autografting), i.e. transplantation of living tissue from some other site in the same individual.

2. Homotransplantation (homografting), i.e. transplantation of living tissue from another individual.

3. Implantation, i.e. insertion of inert material. This may consist of:

(a) Dead tissue derived from the same or another individual or from an animal. (b) Synthetic substances such as acrylic resin. Heterotransplantation, i.e. transplantation of living tissue from an animal, has also been triedo but has now been abandoned as useless.

Transplants may be further subdivided into̊̊ free transplants, transplants by vascular anasto-mosis and pedicle transplants. A free transplant consists of an isolated piece of tissue which, if it becomes vascularized at all, does so as the result of ingrowth of vessels from the surrounding tissue N In transplantation by vascular anastomosis, on the other hand, continuity between the blood vessels of transplant and host is established at the time of operation. In an experimental animal, for ex? ample, a kidney may be transplanted to the necke with anastomosis of the renal artery to the carotid and the renal vein to the jugular vein. A pedicle transplant remains attached to the donor site untip an alternative blood supply has developed. $A_{\vec{D}}$ homotransplant which remains temporarily at $\frac{?}{\mathbb{D}}$ 
tached to the donor by a pedicle is called a parabiotic transplant.

\section{The Fate of Transplants and Implants}

There are four possible results following transplantation of tissue :

I. The transplant may survive permanently.

2. The transplant may survive for a time and then be destroyed.

3. The transplant may act as a 'scaffolding' and be gradually replaced by similar tissue derived from the host.

4. The transplant may be rapidly destroyed.

Autotransplants commonly survive permanently if infection is prevented and the transplant is provided with an adequate supply of nutrient material and means for the removal of waste products. Transplants of avascular tissues such as cartilage and cornea are nourished by diffusion of fluid from the neighbourhood. With tissues which are normally vascular, on the other hand, a blood supply must be provided or acquired, except perhaps if the transplant is very small. Large transplants are unlikely to survive unless made by using a pedicle or by vascular anastomosis.

In the special case of transplants of endocrine tissue a further condition for survival is that the host must be markedly deficient in the endocrine in question.

Homotransplants may survive for a few days or weeks, and may form useful scaffolding for the growth of host tissue, but permanent survival does not ordinarily occur. There are several exceptions to this rule but only two of them are at present of clinical significance, viz.:

I. Transplants of cartilage may survive unchanged for years.

2. Transplants between identical twins behave like autotransplants.

The destruction of a homotransplant appears to be due to the development of a state of active immunity in the host. Despite much experimental work little is known of the nature of this immunity or of the mechanism by which it brings about destruction of the transplant. A fuller discussion of this subject with a bibliography may be found in the annals of the Royal College of Surgeons for August 1952.

From a surgical point of view the important distinction is between transplants which are useful and those which are not. The most useful transplants are ones which survive permanently or which form an effective scaffolding; as we shall see later, however, temporary survival is sometimes of value.

With implants it would be misleading to speak of survival since the material is dead ab initio. An implant may be useful however if it remains unchanged and functionally effective for a long $\stackrel{\odot}{\circ}$ time or if it provides a satisfactory scaffolding for $c$ the growth of host tissue.

\section{Sources of Material for Transplants}

The use of autotransplants is obviously limited because removal of the transplant creates a corresponding deficiency at the donor site.

Material for homotransplants must, for the most part, be obtained at autopsy. It must be re- $\overrightarrow{0}$ moved under aseptic conditions and within a $\overrightarrow{\vec{H}}$ short time of death. The safe interval depends on the cause of death and the nature of the tissue; it $\frac{D}{D}$ probably never exceeds five hours and for some tissues may be less than an hour. Limited quantities of skin may be obtained from voluntary donors, and tissue removed in the ordinary course

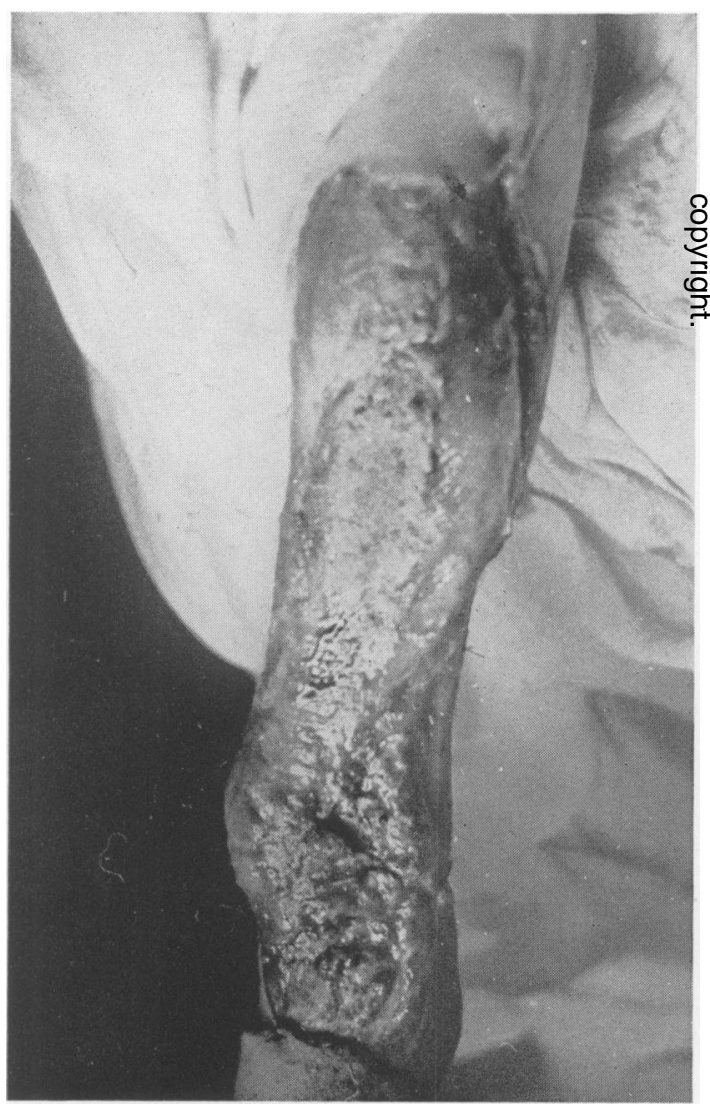

FIG. I.-The patient, a boy of 9 , was run over and lost 90 sq. in. of skin. Seven days after the accident the defect was covered in one operation with splitskin grafts which included two homotransplants each 6 in. $x$ I $\frac{1}{2}$ in. The leg before grafting. 
of surgical operations is occasionally of value (e.g. ribs removed during thoracoplasty).

\section{Methods of Storage}

It is often impracticable to use fresh material and various methods of storage have therefore been devised.

When the tissue is to be used as a transplant it must of course remain viable. This may be achieved by storing it in a mixture of plasma and a balanced saline solution or by freezing at low temperature. When all that is needed is an implant the tissue may be immersed in an antiseptic solution such as merthiolate.

\section{Surgical Applications}

We shall now consider some practical examples illustrating the present scope of surgical replacement therapy.

\section{Replacement of Skin}

Autotransplants. Autotransplants of skin should be used in preference to homotransplants whenever

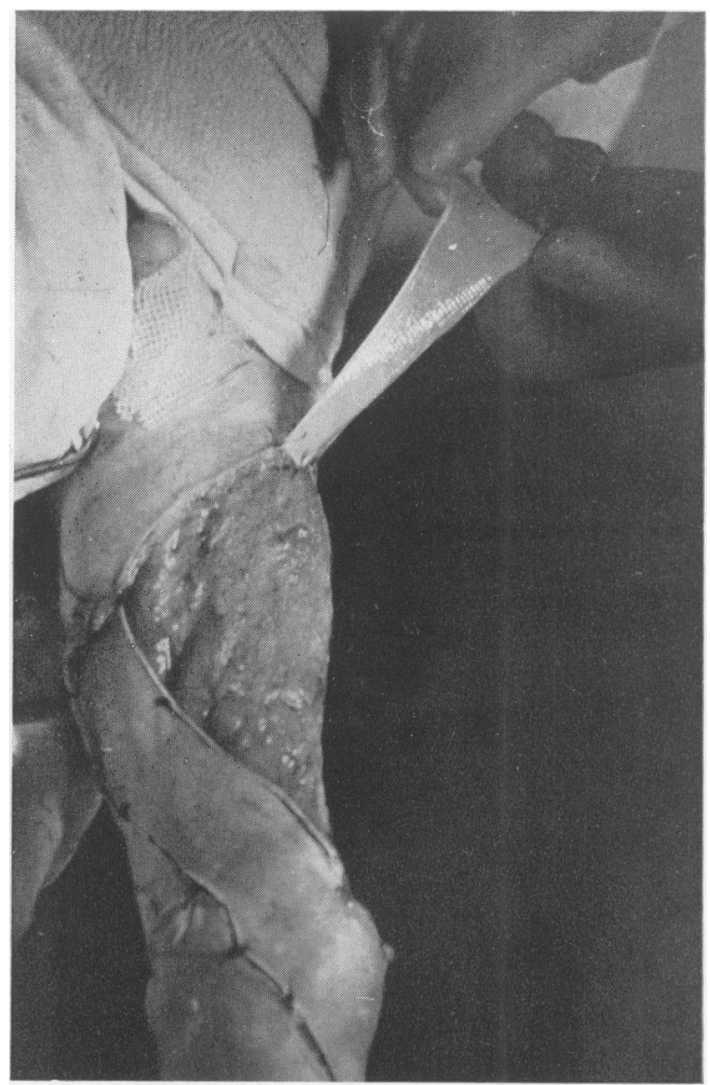

FIG. 2.-Applying the transplants in strips $I_{\frac{1}{2}}$ in. wide.

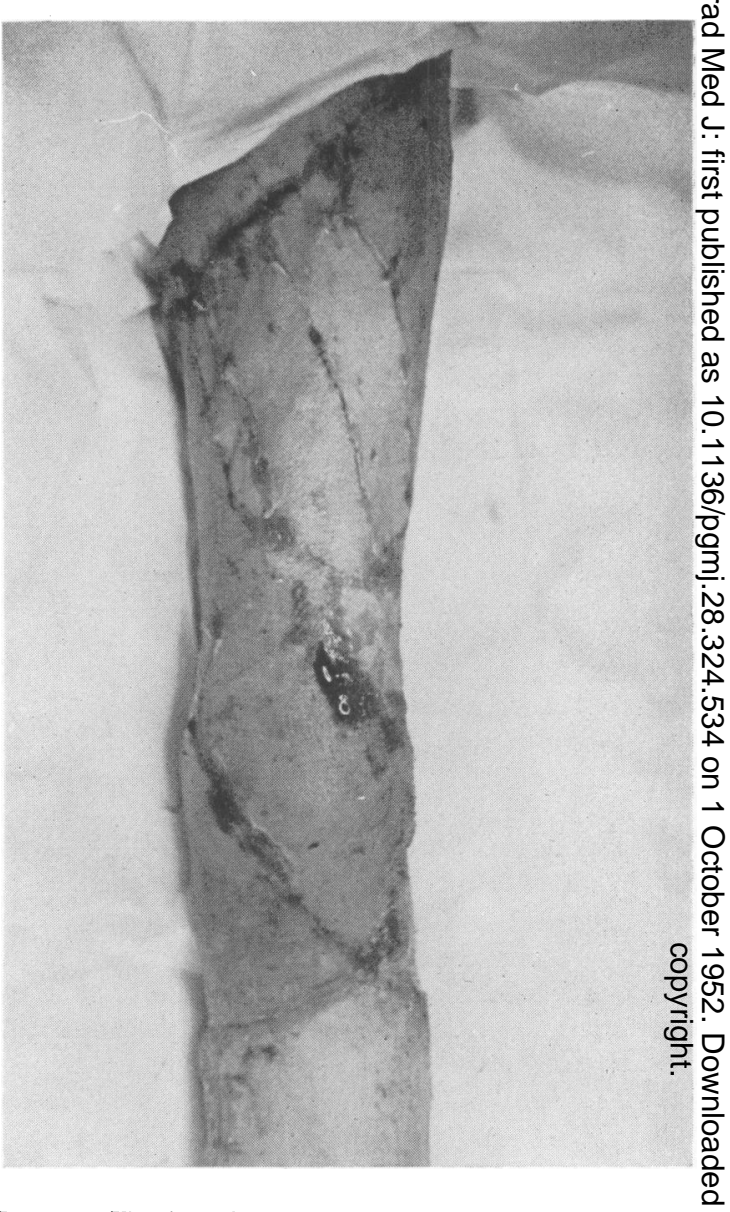

FIG. 3.-Twelve days after grafting. All the transplants have taken well and the homotransplants are윽 indistinguishable from the autotransplants.

possible, but sometimes when there has been extensive skin loss (e.g. in severe burns) it may be 3 . impossible to cover the defect adequately witho autotransplants. The various techniques ordinarily used in skin grafting are well known andô need not be described here.

Homotransplants. Homotransplants of skin음 ' take' almost as readily as autotransplants but $>$ are subsequently destroyed; the usual period of survival varies from about ten days to six weeks. N Claims of permanent survival have been made but ${ }^{\circ}$ are unconvincing except in the special case of transplantation between identical twins.

Despite this homotransplants may be valuable? because by using them it is possible to cover aco large defect at an early stage and in one operation. Only free transplants should be used, preferably $\stackrel{\oplus}{+}$ of split skin. Parabiotic transplants have been 0 tried but are likely to provoke a serious reaction in $\frac{\vec{\Phi}}{\mathbb{D}}$ the recipient. 


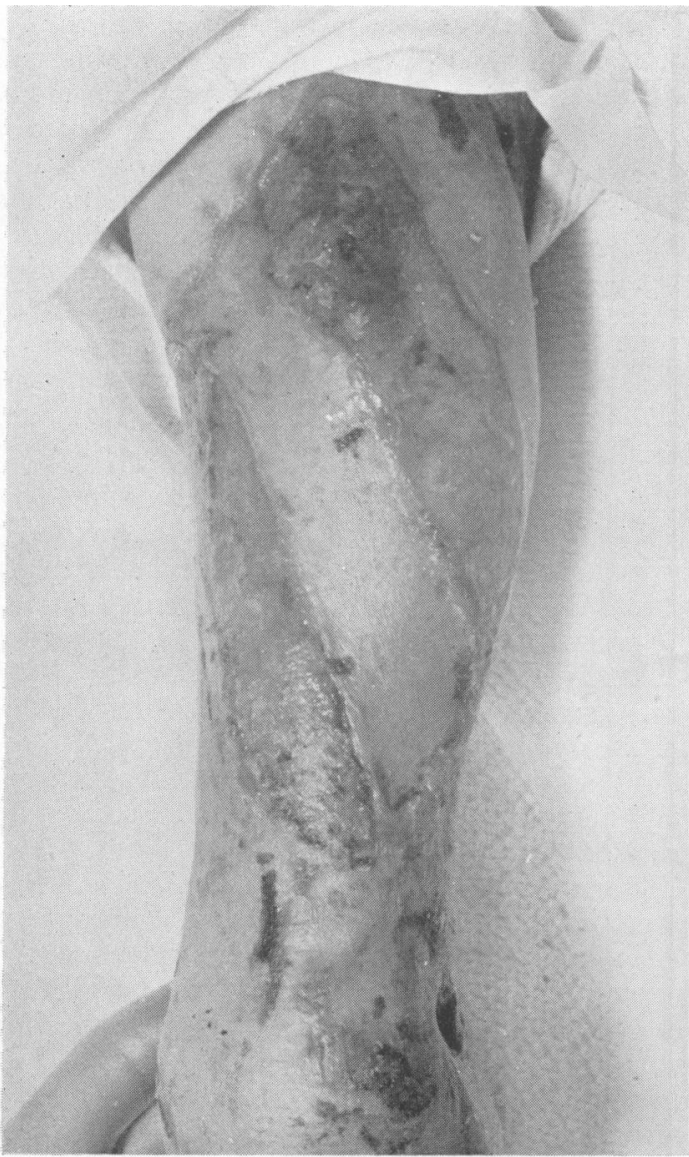

FIG. 4.-Six weeks after grafting. The homotransplants have been destroyed leaving clean granulating areas. These were covered with further autotransplants from the original 'donor sites.'

The best method is to use alternate strips of autologous and homologous skin which have been cut with a dermatome. When the homotransplants have been destroyed further autotransplants may be used to cover the raw areas. These new transplants may, if necessary, be obtained by recropping the sites from which the original autotransplants were obtained. They usually take readily (Figs. I to 5).

Attempts are being made to increase the period of survival of homotransplants by matching donor and host, by using multiple donors, and by giving cortisone or ACTH.

Matching donor and host. If transplants of equal size are made from a single donor to several recipients the period of survival of the transplants varies from patient to patient. Conversely, if a given recipient receives transplants of equal size from several donors the period of survival varies from transplant to transplant. It follows that better results would be obtained if one could select in advance the most suitable donor.

Is blood grouping of any help? It seems reasonable to choose a donor of the same group as the recipient whenever possible, but in practice compatibility of $\mathrm{ABO}$ and $\mathrm{Rh}$ grouping appears to make little difference to the period of survival of the transplants. Whether refinements of red cell typing will help to solve the problem remains to be seen.

Use of multiple donors. A large transplant (or a series of small transplants) from a given donor to a given recipient is likely to be destroyed more quickly than a single small transplant; indeed if a large area is covered with skin from a single donor the transplants may be so short-lived as to be of no value. The average period of survival is much greater, however, if the transplants are

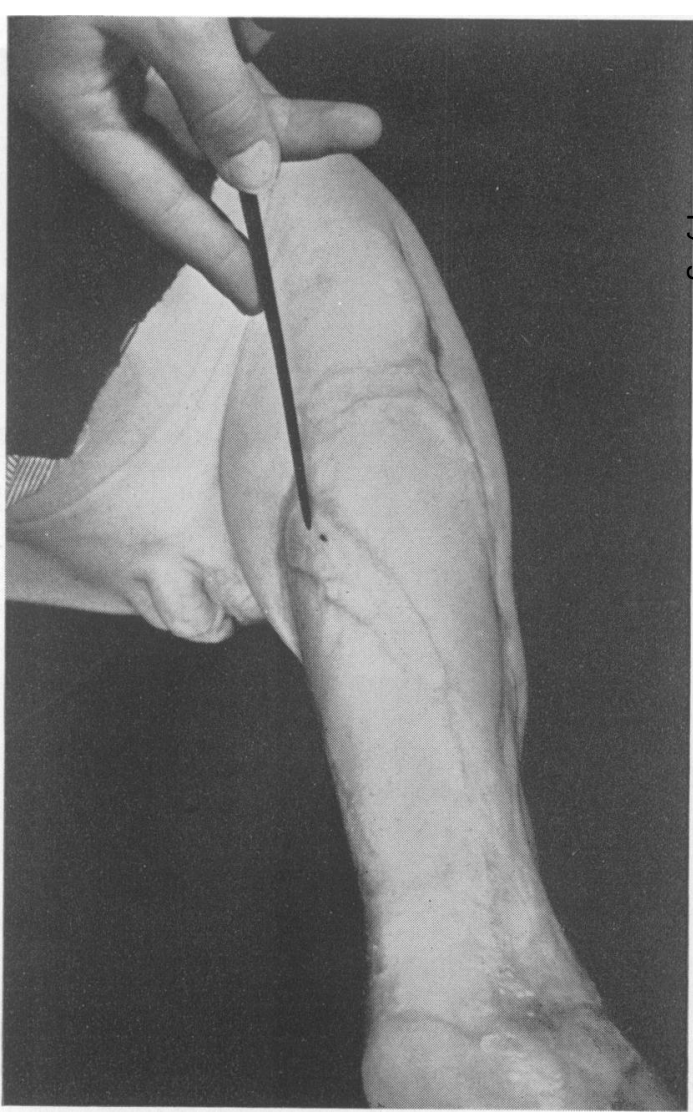

FIG. 5.-Six months after grafting. The second set of autotransplants, replacing the homotransplants, have taken well. The areas they cover, one of which is indicated by the pointer, have contracted but the functional result is excellent.

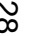
$\omega$ 
taken from several different donors. This is because the immunity induced by each transplant is partly specific for the individual donor, i.e. it is less effective against transplants from other donors. The total resistance to a given transplant is therefore the sum of a large component induced by itself and a series of small components induced by the other transplants.

In practice at least two donors should always be used, and with large defects it is best to use three or four donors.

Use of Cortisone and ACTH. Cortisone and ACTH have a profound effect on many immunological phenomena and it is therefore not surprising that these substances have been used in the hope of prolonging the survival of homotransplants. Experiments in various laboratory animals have yielded conflicting results but it has been established that the period of survival of skin homotransplants in the rabbit can be increased by giving cortisone systemically or by applying it to the surface of the transplants. The matter is being investigated in man but so far the results are disappointing.

Storage. Provided it is kept moist, skin for transplantation may be stored for at least two weeks in an ordinary refrigerator $\left(4^{\circ} \mathrm{C}\right.$.).

Long-term storage at lower temperatures is being investigated.

Use of human amnion in the treatment of ulcers. During the last few years human amnion has been used in the treatment of chronic varicose ulcers and encouraging results have been reported. The amnion is usually boiled and is therefore an implant and not a transplant. It is firmly applied to the raw surface and the leg is enclosed in plaster. The amnion overlying the ulcer disappears in a few weeks, but in the meantime epithelium starts to grow inwards from the periphery. Two reasons, both of them speculative, have been suggested for this:

(a) The amnion provides a surface along which epidermal cells can readily migrate.

(b) Chemical substances are liberated from the amnion which specifically stimulate epithelium growth.

Of course, immobilization and elevation alone may promote healing, but many of the ulcers successfully treated with amnion are said to have resisted all other treatment. Certainly the method warrants further investigation.

\section{Transplantation of Cornea}

Homotransplantation of cornea is now a wellestablished procedure for the treatment of corneal opacities and keratoconus, and gives a good functional result in many cases.
There has been much speculation as to why corneal homotransplants survive; it now seemsD probable that they do not survive permanently bue are gradually replaced by host tissue. The success of the operation depends on whether or not this? replacement occurs in an orderly manner and without accompanying vascularization.

For technical details of corneal transplantationf the reader should consult a textbook of ophthalmiç surgery.

3. Transplantation and Implantation of Bone and
Cartilage

If infection is prevented homotransplants of cartilage and implants of dead cartilage preserved in alcohol or merthiolate usually persist for many. years. They have been used successfully for re- $-\infty$ construction of the pinna in cases of congenital deformity, for reconstruction of the bridge of the $i$ nose, and in other plastic operations. In view of the morbidity which sometimes follows the re-o moval of autologous costal cartilage it is surprisingthat homologous cartilage is not used more extensively.

The use of autotransplants of bone in ortho-윰 paedic surgery is well known. Small autotransplants of cancellous bone survive permanent Autotransplants of compact bone, especially if they are large, do not survive, but they act as scaffoldiog and as local depots of calcium, and if placed in contact with living bone they are gradually reconstituted.

Homotransplants and implants of dead human $\stackrel{\circ}{\stackrel{2}{\varrho}}$ and animal bone behave like autotransplants of $\overrightarrow{\vec{A}}$ compact bone. If used in the form of small chip grafts they are very nearly as good as autotrans- $\bar{D}$ plants for the treatment of ununited fractures, for arthrodesis of joints including spinal fusion, and $\overline{0}$ for filling cavities after the removal of bone cysts. 3 . Massive homotransplants, on the other hand, are decidedly inferior to autotransplants.

Homotransplants of bone were first used $\delta$ clinically by Macewan over 70 years ago, but it is only during the last few years that they have been $ᄋ$ widely used. This recent increase in popularity is due mainly to the development of efficient methods of storage and the establishment of $\bar{N}$ ' bone banks.' Bone transplants may be stored in citrated blood or frozen at low temperatures; 0 implants are best preserved in merthiolate.

\section{Replacement Therapy in Vascular Surgery}

Over 40 years ago Carrel and Guthrie showed that it was practicable to replace an excised segment of a vessel by an autotransplant or homo- $\frac{0}{3}$ transplant. Interest in this subject has been $\frac{\vec{\Phi}}{0}$ revived as a result of two recent developments:

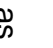

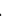


(a) The development of surgical methods of treating congenital disorders of the heart.

(b) The discovery that in peripheral vascular disease the symptoms are sometimes due to a localized block involving a few inches of a main artery.

In congenital heart disease arterial homotransplants have been used successfully in the Blalock-Taussig type of operation when straightforward anastomosis was impossible without undue tension; and in the treatment of coaractation of the aorta, when the length of segment excised was too great for repair by end to end anastomosis. In peripheral arterial disease an occluded segment of artery may be excised and replaced by an autotransplant of vein or by an arterial homotransplant. The tissue of the homotransplants does not survive permanently but is slowly replaced by endothelium and connective tissue from the host.

Segments of arteries for transplantation are obtained at autopsy, preferably from young subjects with no trace of arterial disease. They may be used fresh but this is seldom convenient and several blood vessel banks have now been established. At the Boston Children's Hospital, Gross stores arterial transplants in a plasma-saline mixture. At. St. Mary's Hospital, Eastcott and Rob freeze the transplants quickly in liquid nitrogen and store them in glass tubes surrounded by carbon dioxide snow and kept in a deep freeze.

The technique of anastomosis is similar to that described by Carrel. Two stay sutures are inserted and one of these is continued as an everting continuous mattress suture. The danger of thrombosis is much less if heparin is administered postoperatively; the suturing must therefore be sufficiently accurate to permit this.

\section{Homotransplantation of Endocrine Tissues and Kidney}

The idea of treating patients with endocrine deficiencies or extensive irreparable renal damage by means of homotransplants is intriguing. Much experimental work has been done in this field but the results so far are disappointing, and despite the occasional claims of successful homotransplantation of the kidney by vascular anastomosis, and of suprarenal and parathyroid gland, these procedures must at present be regarded as dangerous and unlikely to succeed.

Will the problem of making homotransplants of endocrine and other tissues which are capable of surviving and functioning for an indefinite time ever be solved? Time alone will tell but present indications justify an attitude of cautious optimism. If a solution is found it should mean the beginning of a new era in the history of surgery.

\title{
SOME NOTES ON WILM'S TUMOUR
}

\author{
By G. L. Bunton, F.R.C.S.
}

Nephroblastoma is an uncommon growth, in spite of the fact that it accounts for a high proportion of malignant disease in childhood. It is known as Wilm's Tumour, although Gairdner first described it in 1828 .

It does not fall to the lot of the general surgeon to see many of these patients. Indeed only two have been admitted to the Westminster Children's Hospital during the last two years. Ladd and Gross, who have had as great experience as anyone of this condition, collected 54 cases from a large area of the United States of America. In adults it is very rare. Esersky collected 54 cases from the literature and added three of his own.

The recent admission to this hospital of a particularly rapidly growing tumour in a little girl aged five unexpectedly revealed sharply divergent views on treatment. The argument is an old one and has not yet run its course. It is irradiation versus surgery. Before the advent of irradiation the outlook was poor and, even since, few patients have been cured. Ladd and Gross report 13 survivors out of 54 patients, their life-span ranging from a few months to twenty-one years after treatment. They state that if there is recurrence, it is within the first 9 months in 95 per cent. of patients.

Until recently pre-operative irradiation was advised, sometimes followed by similar postoperative treatment. After three to five weeks a previously large mass might become operable and even impalpable; the risk of metastasis was said to be less during the disturbance of the operation. This is perhaps rather a vain hope as over half the patients have demonstrable metastases when first 